\title{
The Need to Evaluate Urban Green Spaces in the City Core in Bengaluru
}

\author{
Ar. Sreesha S Bhat, Monalipa Dash
}

\begin{abstract}
With the rising demand for the study on various factors impacting the microclimate and the parameters influencing the quality of life in cities today, the evaluation of the different socially active zones or more specifically, the green areas on the city limit has become equally important to consider for researchers who mainly deal with the growth of urban areas. Accordingly, the aim of this research is to analyse such green spaces located at the city core, either historically located as voids in the city core to organise the development or originally drawn by planning authorities, so as to add as some catalyst activity zones amongst various other urban land uses. Henceforth, more like a descriptive research approach was adapted which was based on number of literature studies, documentation of the typology of green spaces, field visits of the identified green areas and direct observations drawn during the visits. Such a type of descriptive investigation helps in identifying the impact of these green spaces towards the immediate surroundings and also the other factors like economic and ecological attributes that affect the quality of life nearby. The investigation for the noted open spaces in this study have mainly two components, one being the qualitative measuring tool and the other being the quantitative measuring tool. In the first stage the quantitative analysis records sky view factor, that helps in defining the shading intensity in a particular open space, while in the second stage, the qualitative analysis like building use around the green space and the type of activity documented helps in defining the relationship between both the stages of analysis to infer the quality of the open space and their impact of the immediate surrounding. Finally, based on the analysis, the inference of the kind of activity in the open space and the kind of end user is directly proportional to the relation between the intensity of shade and the urban land use type adjacent to the open space respectively.
\end{abstract}

\section{INTRODUCTION}

How cities have started growing rapidly, similarly, the inhabitants residing in these cities have a noticeable change in their lifestyles. Most cities in India lack quality of open urban green spaces, that help in directly or indirectly enhancing the quality of the lifestyle of the residents of the city. However, the minimum prescribed by World Health Organization (WHO) open space per city dweller is about 9 square meters [Kuchelmeister, 1998] and unfortunately, cities like Bengaluru which has only 3 percentage of green space in the city core hardly meets the requirement with just about 2 square meters per city dweller. These voids in the city not only referred as 'lung spaces' improve the ecological balance in the fast growing growth but also, they better the social interaction between various people in the city. These green spaces in the city further act as catalyst for social interactions that help in manifesting the betterment in the ecological, social, visual, morphological, and perceptual

Revised Manuscript Received on July 10,2019.

Ar. Sreesha S Bhat, Nitte Institute of Architecture, Mangalore, Karnataka, India..

Monalipa Dash,India dimensions of a city. Thus, these spaces deserve consideration in terms of both meeting urban and environmental needs and providing leisure spaces and making a context for communication and its social equilibrium [Kiani, Akbar \& Javadiyan, Masoume \& Pasban, Vahid. (2014). Evaluation of Urban Green Spaces and their Impact on Living Quality of Citizens (Case Study: Nehbandan City, Iran). Journal of Civil Engineering and Urbanism. 4. 89-95.]. Urban green spaces which technically can be defined as a particular space that is open to sky, permeable in surface, and accessible to public is more a rare than a rule today. There are hardly few urban green areas satisfying all the basic necessities to be called the same, and most importantly, even if a green space satisfies the same, the question is, till when can the open space cater to the general public due to lack of maintenances by the governing body or the immediate public using the space [New York State Open space Conservation Plan 2016, Andrew M. Cuomo, Governor]. Defined as social spaces in an urban setting, the demand of such quality spaces is directly proportional to the population density of the city. Further, these open spaces also create a system dependent program in the urban setting. On one aspect if one could address the growth of the cities being a major threat to ecological dimension of the city in terms of quality of air, sustainable living, and thermal comfort, it also on the other hand holds responsibility to answer the difficulty the civilians face in the social dimension of the city, thus reminding the importance to maintain these urban voids. Most of these urban parks or open spaces have the complete potential to attract many people for social interactions and as well as support undesired activities or crime. However, these urban green spaces mentioned mostly include easily accessible places in the city such as plazas, parks, traffic nodes, pedestrian friendly streets and so on [Ceccato, V., \& Newton, A. (Eds.). (2015)]. There have also been many policies and guidelines put in force to improve the quality of these green spaces taking the above mentioned issues into consideration. Hence further discussing the parameters that affect the quality of an urban open space, this paper attempts to analyse the relation between the influential factors to the activity prioritised in an open space in Bengaluru city core.

\section{METHODOLOGY}

The study is done in two stages:

1. Analysing the adequacy of open spaces in the CBD through land use. 
1.1 Inspecting the land use maps of the identified site, with the marking of specified green areas in the masterplan, which further helps in questioning the justification of the same.

2. Analysing the quality of open spaces

2.1 A quantitative reading of how well shaded is the green space is analysed by calculating sky view factors at multiple points in a green space.

2.2 Secondly, repeated site visits are conducted to record the various necessary details about the site, such as;

\subsubsection{Building Use, and}

2.2.2 Activity mapping

Surface quality, Parking, Access points, density zoning shall add to the analysis of the specific site characteristics. To conduct the above mentioned study, a set of figure ground diagrams showing the immediate surrounding of the green space would help in understanding the same [B.D. Wortham-Galvin (2010). Footprint; Drawing Theory, Autumn 2010, pp. 59-74]

3. These inspections on site shall help in inferring the relation, an urban open space has between factors such as shading intensity and the kind of activity and density it supports.

\section{CASE STUDY}

Bangalore is situated in the southeast region of Karnataka State in South India, at an average elevation of $920 \mathrm{~m}$ above mean sea level. It is positioned at $12.97^{\circ} \mathrm{N}, 77.56^{\circ} \mathrm{E}$. The contour of the city is flat except for a ridge in the middle running north northeast to south southwest. With no natural features restricting its development, the spatial growth pattern of Bengaluru city is characterised by urban sprawl. A scale comparison of Bengaluru with other comparable mega cities in India reveals that it is the city with the largest spatial extent of urbanisation. Bengaluru's physical footprint has increased by over $100 \%$ from 1992 to 2009 with a $134 \%$ increase in built up area, accompanied by a sharp decline in water bodies and natural vegetation [Census of India, 2011; Indian Institute for Human Settlements (IIHS), 2009; Ramachandra and Kumar, 2009]. In addition, Bengaluru's population has grown by over $40 \%$ in the last decade to reach an estimated 8.5 million in 2011. As the densities of population are increasing, the risks to people, services and economy are also increasing. Developments in low lying areas, particularly informal settlements are most exposed to flood risks. Residents in Bangalore are particularly vulnerable to hazards such as urban heat island effect, urban floods, and water scarcity because of rapid and unplanned urbanisation, most of which will be exacerbated by climate change. Bangalore faces considerable socio-economic and environmental risks if it were to continue on its current development pathway [Wankhade, Kavita \&, IIHS. (2014). Future Proofing Indian Cities: Bangalore Diagnostic Report. 10.13140/RG.2.2.10460.59524]. Governance in Bangalore is also fragmented, making coordination across different agencies challenging. It has significant potential to play a major role in the future development of Karnataka and Southern India. However, to continue to leverage its knowledge-based economy, the city needs to address multiple challenges across a range of sectors. A significant proportion of the city's population lives in slum areas. The city is also growing rapidly, creating challenges in ensuring the provision of adequate infrastructure, housing, and basic services to meet the growing demands of its residents.

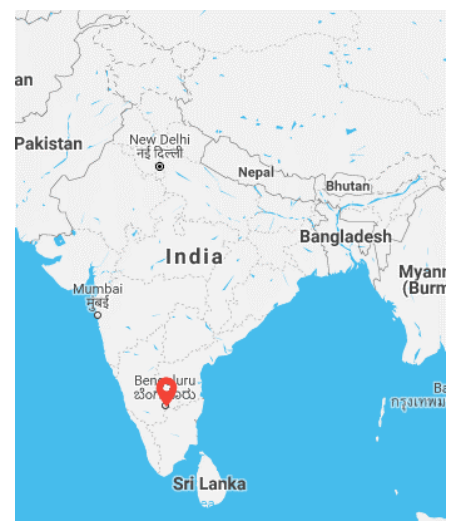

Figure 1: Location map of Bengaluru

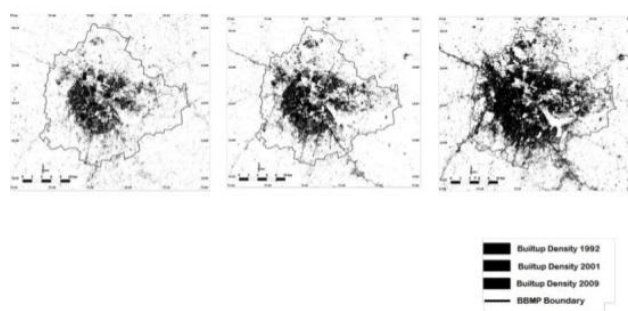

Figure 1: Growth of Bengaluru Source: Wankhade, Kavita \& , IIHS. (2014). Future Proofing Indian Cities: Bangalore Diagnostic Report. 10.13140/RG.2.2.10460.59524.

Hence, the site selection process based on all the above mentioned facts, has led to the area in the central business district of the city, spanning to about 2.24 square kilometers, called the petta region.
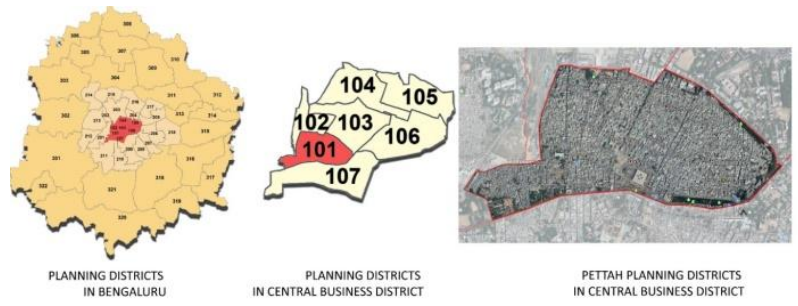

Figure 2: Location of Petta in Planning District map

The area selected lies in the CBD area of the city neighbouring to the planning districts inside the first ring road; Majestic, Gandhinagar, Vasanthnagar, Shivajinagar, Richmond Town and Chamrajpet, according to the revised master 2015 for Bangalore city.

\section{OBSERVATION AND ANALYSIS}

\section{Open space percentage based on land use}

In spite of the total area being around only 2.24 square kilometre in area, the population density is fairly dense with about forty thousand people per square kilometre of area,

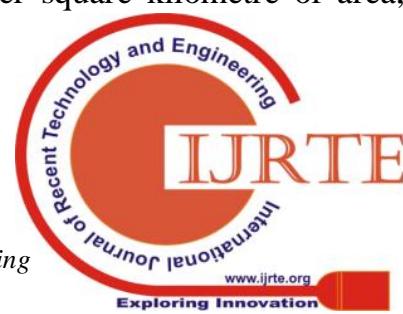


and admitting that a noticeable percentage of them could be floating population, yet the percentage of denoted green area for this planning district is relatively less adding to just about 2.7 percentage of the total area.

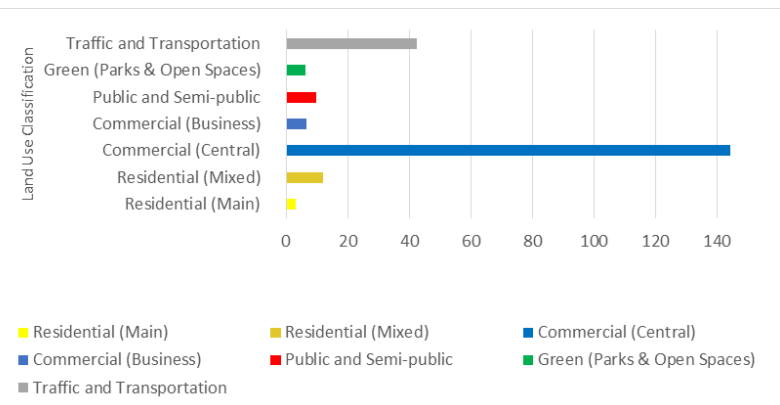

Figure 3: Land Use Classification in Petta

The examination of these green areas makes it indispensable to gain clarity on the type of impact these areas are creating in the city core.

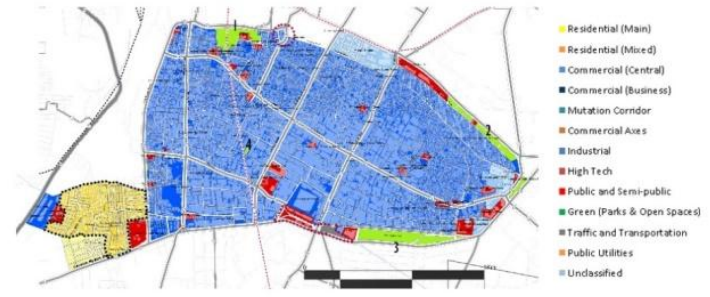

Figure 4: Land Use map of Petta Planning District

As shown in Figure 5, all the existing green areas as per the land use map were pilot surveyed and numbered based on the hierarchy of their area, and further audited.

\section{Quality of open spaces}

The audit for these green areas give an idea of what kind of the open areas each of them are, further helping to categorise them in the larger picture. It also helps in understanding the multiple features of a single open space. In some areas it helps in knowing the location of these open spaces much better through their proximity to the nearest landmark.

Table 1: Urban Audit for Green spaces in Petta

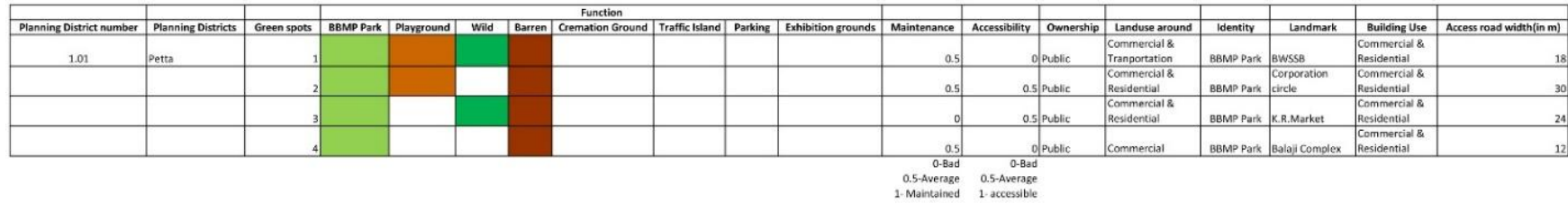

\section{Analysis}

\subsection{Stage one}

\subsubsection{Sky View Factor (SVF) Mapping}

As mentioned earlier, in the stage one, all the four existing green spaces are analysed quantitively through the sky view factor parameter to understand the intensity of shading in them.

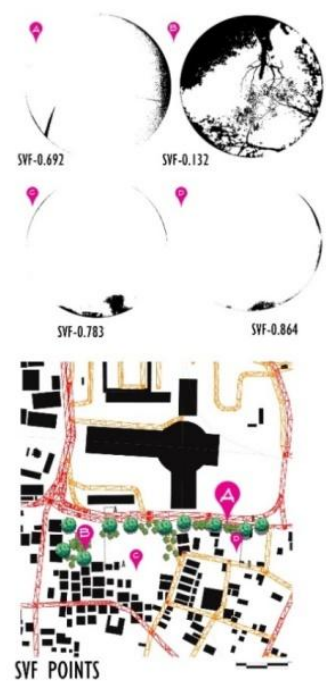

Figure 5: Green space 1: SVF analysis

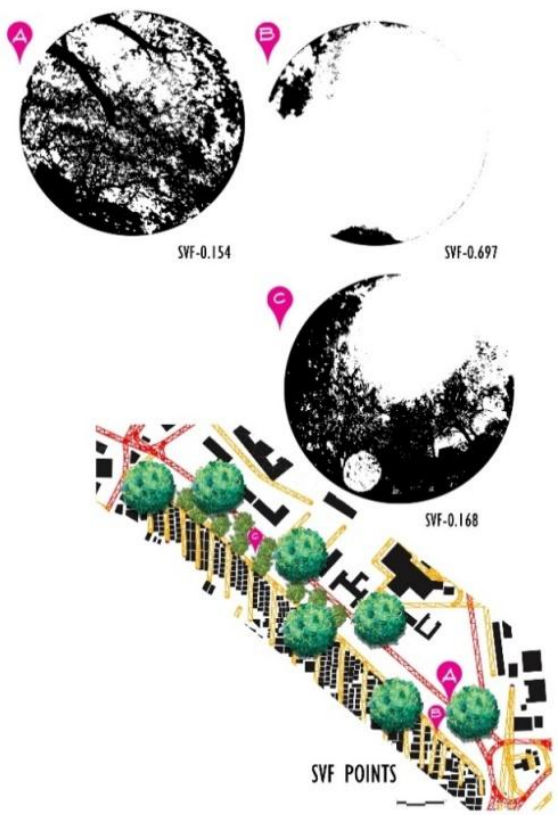

Figure 6: Green space 2:SVF analysis

Note: Sky View factors: The SVF from point A, B, and $C$ shows the shading intensity at respective pinned locations in the plan below.

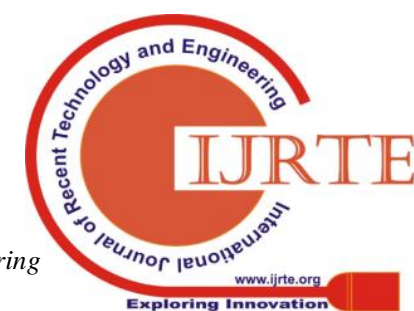




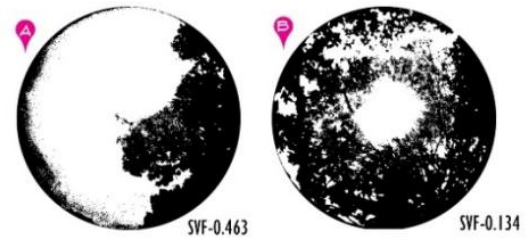

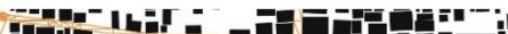

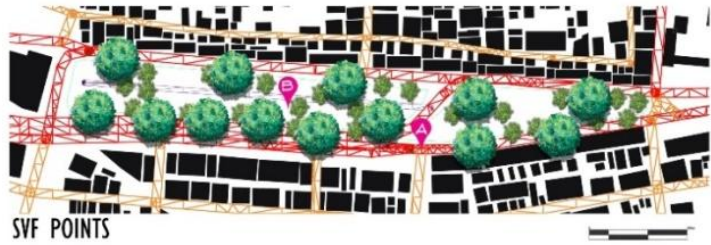

Figure 7: Green space 3: SVF analysis
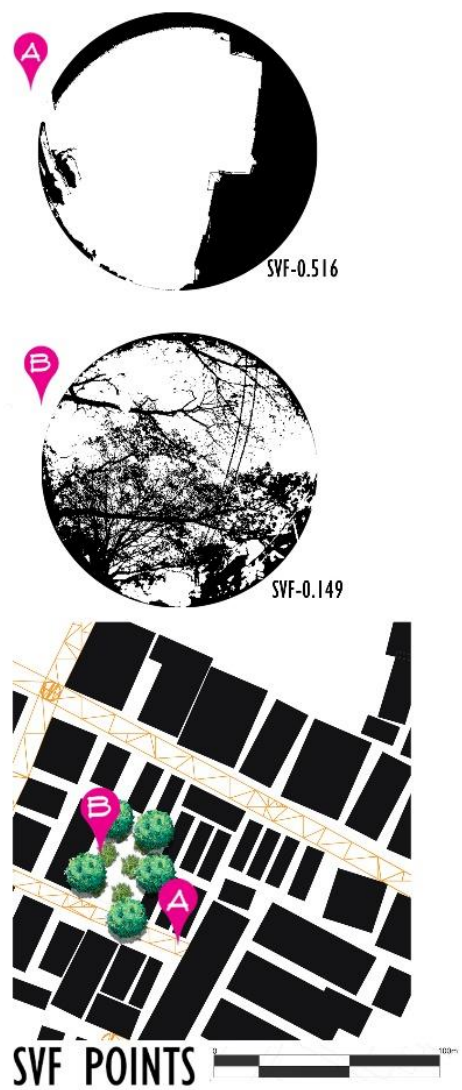

Figure 8: Green space 4: SVF analysis

\subsubsection{Observations on Sky view Factors}

Interestingly, although all the green spaces in this planning district are located amidst the high density built, emphatically, the majority of these spaces are shaded by vegetation, and there are very few areas, where the open space is left unshaded. Emphatically, the intensity also helps in deciding an optimum shape for a green space located in a dense urban fabric. The above figures (Figure6-9) show how the shading intensity varies from one open space to the other. Green space 1, also known as the Lokmanya Tilak Park, is the only open space which wide range of shading intensity, where part of the open space stays unshaded. However, the function of the Moreover, the green areas in the petta area remain shaded by vegetation or the buildings, the reason being the shape and scale of the park, and not just the presence of dense vegetation. Very clearly, although sandwiched in between unshaded region keeps the playground occupied.

two major streets, the geometry of the green spaces two and three keeps them well shaded, where both these open spaces have a very narrow and long, taking shade from vegetation on both sides of the street. However, some part of the green space 2, also called as Bannappa Park, has no shade, resulting it in acting as playground for the neighbourhood. Thus, it is understood that the open space transforms itself from a neighbourhood park to a playground based on the shading intensity and the ground surface type.

\subsection{Stage two}

The second stage consists of the analysis conducted in a qualitative way. Here, parameters such as activity zoning, and individual building use, are recorded to analyse the impact of the building use, the corresponding land use, on the kind of activity in the open space.

\subsubsection{Activity and Building Use mapping}

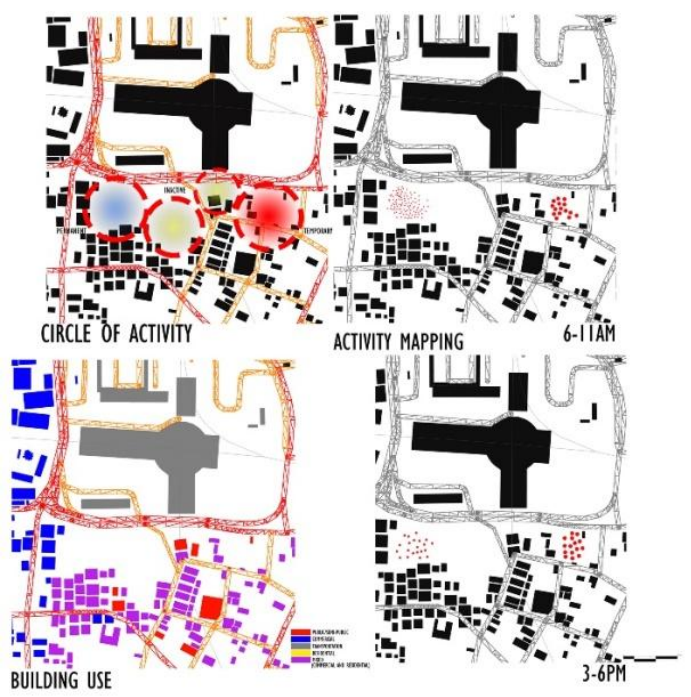

Figure 9: Green space 1: Stage two analysis

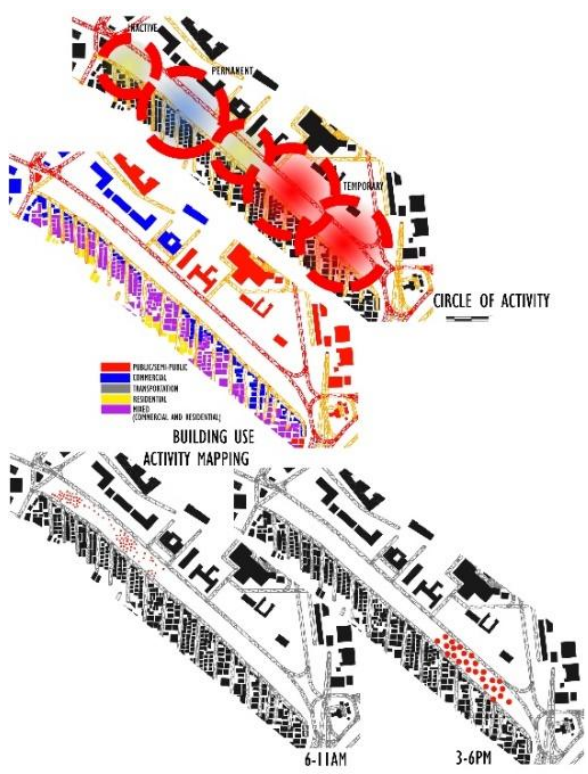

Figure 10: Green space 2: Stage two analysis

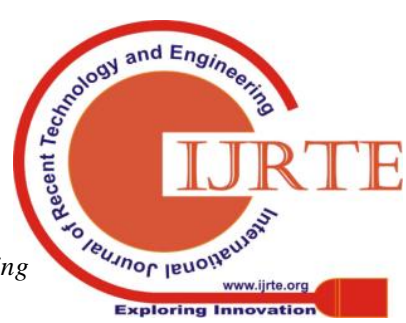




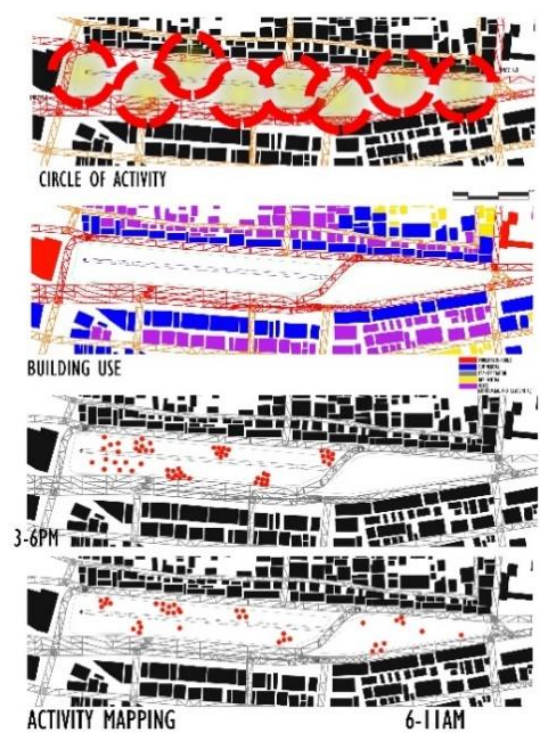

Figure 11:Green space 3: Stage two analysis

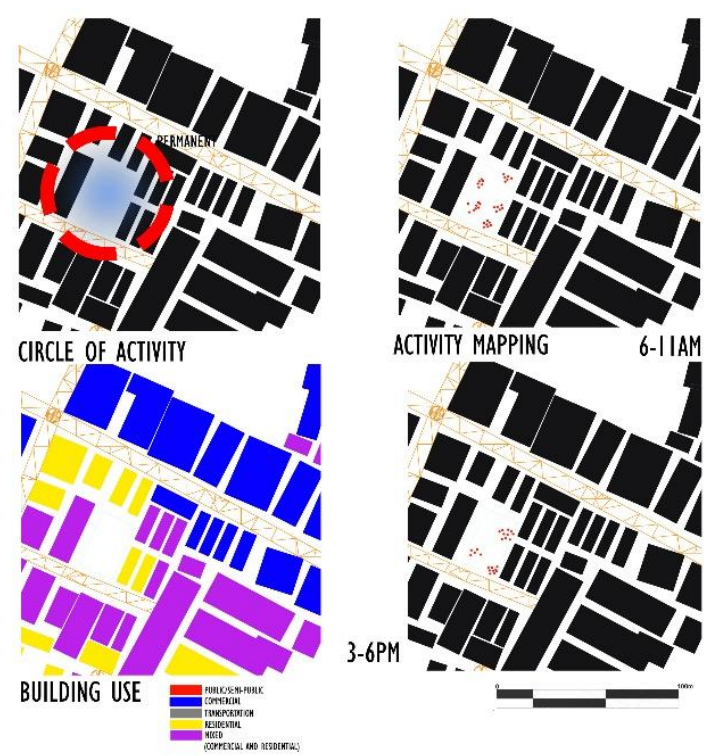

Figure 12: Green space 4: Stage two analysis

\subsubsection{Observations from Building use and Activity mapping}

The 'circle of activity' in all the above figures shows the type of activity, which is based on the duration a particular activity takes place. Like, how green space one and two, have the maximum diversity of activities in it, where the eastern part of the park acts as a playground, marked as a temporary activity, there are some inactive zones where the green space is left unattended, and the leisure park area denoted as permanently active zone. Regrettably, green space three and four, do not attract much people, although vitally placed amidst the commercial zone.

The 'Building Use' maps help in analysing the end user of the park by knowing the immediate surrounding. However, these maps help in justifying the activity in the green space based on the building use. In most cases, the green spaces are acting as transitional spaces, especially, in green space one and two, where the building use is completely different; from transportation to mixed use in the first case, and from commercial and institutional to mixed use on the second case. In case of green space 3 , also called as Silver Jubilee park, the building use remains similar till the first ring of built; and the open space placed in close proximity to the wholesale commercial zone, the immediate surrounding here has made maximum impact on the green area making it dead green space, with very little social interaction. As an exceptional case, the fourth green space enclosed mostly by mixed use built with predominant residential use, have scopes to appreciate some social interaction.

'Activity mapping', further tries to justify the role of the green space by relating the 'circle of activity' and the 'building use'. This gives an idea of the density of people the park engages during different time of the day. Activity mapping for the green space one, showed some important observations like the park area of the green space one, is seen more active in the morning hours than in evening hours, whereas most of the BBMP (Bruhat Bengaluru Mahanagara Palike) parks see the same density both during morning and morning hours. Ironically, Bannappa park, records more density of people during the evening hours, and morning people are mostly just trespassers of the park. Sadly, green space three and four doesn't witness many people like any other parks, because of the immediate surrounding land use and the scale of the open space respectively.

\section{RESULTS AND DISCUSSION}

Although, the urban audit mentioned in the beginning, roughly categorises all the authenticated green spaces in the petta area, the detailed analysis gives a better picture in understanding the quality of each of these open spaces in particular and the impact the civilians are having by consuming them. Inferring the observations, all the parameters taken into consideration gives clarity in a particular dimension, the green space functions. Furthermore, relating these parameters of study gives rise to interesting discussions. For instance, green space one and two separated by about just 1.5 kilometres attracts an entirely different density of people, although having recorded similar building uses adjacent to the open space, and activity zones in the park. Hence, can it be inferred that the density the park caters to also depends on the area and geometry of the open space? If Geometry and scale plays an important role, Bannappa Park records more density than the silver jubilee park, both having almost similar geometry and area. Here, the building use is the predominant parameter that majorly affects the jubilee park. The urban structure, where the jubilee park is sandwiched between major streets of the city also matters for the quality of the open space. Some exceptional green space like the fourth green space recorded in the pettah planning district also faces contradictory peculiar issues such as the scale of the open space and the narrow streets adjacent to them. These local streets although narrow, carry irregular traffic density, because of the wholesale commercial land use in close proximity. This makes the surrounding of the park very unfriendly for people to

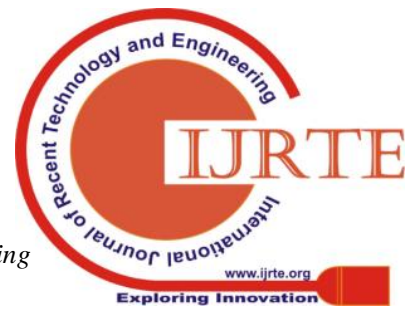


access it. Thus, in spite of the fourth green space meeting almost all the ideal requirements for a neighbourhood park yet have some minor deficiencies in fulfilling them.

\section{SUMMARY AND CONCLUSIONS}

The integrated analysis of both the tangible and intangible parameters have showed that this integration is an important process for evaluating green spaces and their significance in a city. This is because the two aspects have the ability on qualitative and quantitative data analysing and they have advanced tools that can deal with different kind of scenarios in the city limits. The analysis template generated has showed its effectiveness and the ability on generating subsequent inferences on the urban ecology and their impacts on larger areas of concern like the change in micro-climate and heat island effects in the city core with very less effort. Also the flexibility in similar kind of analysis is helped for mapping the different local climatic zones inside the city limits in further stages. So the range of parameters that were generated was reliable in terms of their diversity inside the city core area. However, the overall accuracy of the study are acceptable because of the fact that the parameters taken into consideration have shown enough significance on the on the prioritised activity. This research has analysed just a small area in the city core and further can be mapped for the entire local planning boundary limits. In the presented example, the ability of two aspects such as the sky view factor and the building use has been thought reliable and enough accurate, after comparing it with the existing land use maps. Furthermore, the process takes much lesser time to repeat similar process to understand the green areas in other planning districts. Also, the layers mapped showed the effective ability for creating layouts for the extraction of information for different kinds of analysis, such as; Defining UHI magnitude, analysis of climate responsive architecture in the city, city planning guidelines, landscape ecology and many more. Finally, it can be concluded that such evaluation process for the green areas in the city can give precise and better inferences to justify them in the planning process, and in turn can be planned more effectively to enhance the various social and ecological dimensions in the city core.

\section{ACKNOWLEDGEMENTS}

The authors thank The school of planning and architecture, University of Mysore, and Nitte institute of architecture, Mangalore for their kind support throughout the process for the project and writing this paper.

\section{REFERENCES}

1. Bharath H Aithal, Vinay S and Ramachandra T V, 2013. Modelling and Simulation of Urbanisation in Greater Bangalore, India, Proc. of National Spatial Data Infrastructure 2013 conference, IIT Bombay, November 29-30, 2013, pp 34-50

2. Census of India, 2011; Indian Institute for Human Settlements (IIHS), 2009; Ramachandra and Kumar, 2009
3. Revised Masterplan 2015 for Bengaluru, BBMP, http://bbmp.gov.in/documents/10180/505066/1.01+Petta.pdf/727aaaef-f141-44ec-9109-b949efa7e11f

4. B. Holmer, U. Postgård, and M. Eriksson (2001). Sky view factors in forest canopies calculated with IDRISI. Theoretical and Applied Climatology 68, 33-40

5. Johnson G, Watson I (1984). The Determination of ViewFactors in Urban Canyons. Journal of Climate and Applied Meteorology 23, 329-335

6. Wankhade, Kavita \&, IIHS. (2014). Future Proofing Indian Cities: Bangalore Diagnostic Report 10.13140/RG.2.2.10460.59524.

7. Stewart, I.D. and Oke, T.R. 2012. Local Climate Zones for urban temperature studies. Bulletin of the American Meteorological Society, 93: 1879-1900.

8. Kiani, Akbar \& Javadiyan, Masoume \& Pasban, Vahid. (2014). Evaluation of Urban Green Spaces and their Impact on Living Quality of Citizens (Case Study: Nehbandan City, Iran). Journal of Civil Engineering and Urbanism. 4. 89-95.

9. Parham A. Mirzaei, Recent challenges in modeling of urban heat island, Sustainable Cities and Society, Volume 19, 2015, Pages 200-206, ISSN 2210-6707

10. New York State Open space Conservation Plan 2016, Andrew M. Cuomo, Governor

11. Payne, T. C., \& Reinhard, D. (2016). The Complexity of Problem-Solving in Urban Parks: A Case Study. International Criminal Justice Review, 26(2), 134-149.

12. B.D. Wortham-Galvin (2010). Footprint; Drawing Theory, Autumn 2010, pp. 59-74 